\title{
Identification of the design variables of eLearning tools
}

\author{
M.R. Martínez-Torres ${ }^{\text {a }}$, S.L. Toral ${ }^{\text {b, } *}$, F. Barrero ${ }^{\mathrm{b}}$ \\ ${ }^{a}$ Facultad de Turismo y Finanzas, University of Seville, Avda. San Francisco Javier s/n, 41018 Seville, Spain \\ ${ }^{\mathrm{b}}$ E.S. Ingenieros, University of Seville, Camino de los Descubrimientos s/n, 41092 Seville, Spain
}

Keywords:

eLearning

Concept mapping

Information and Communications

Technologies (ICT)

Cluster analysis

Multidimensional scaling

\begin{abstract}
A B S T R A C T
The widespread availability of digital learning resources in a variety of media formats has promoted the proliferation of eLearning systems as an integral part of teaching across all sectors of education. However, these systems are rarely planned in advance taking into account its final usefulness. At most, they are validated through learner experience using the final implemented system. In this paper, a scientific technique called concept mapping is proposed to identify the external variables that should be kept in mind while designing an eLearning tool. As a result, improvements can be programmed to increase its utility in the teaching activities prior to its use. The method has been tested in the development of a eLearning system used for advanced microprocessor teaching. Results are shown through two-dimensional maps, in which variables can be seen as clusters or groups of ideas. These variables can be used as a guide for developing an eLearning tool. The reliability of the results is also analyzed to check the correct application of the proposed technique.
\end{abstract}

\section{Introduction}

The university system is experiencing a deep institutional change caused by the process of globalization (Hagen, 2002). This process is leading to new structures worldwide, both in economic and political levels. One of the European Union objectives is to coordinate the legislation from its State Members, not only in the economical field, but also in the social development (Joint Declaration of the European Ministers of Education, 1999). In the last decade, this objective has been extended to include the Education Area. The Sorbonne Declaration (25th May, 1998) emphasized the Universities' role in the development of European cultural aspects, being the first step in the creation of a European Area of Higher Education to promote citizens' employability and mobility, as well as the Continent's overall development (Musselin, 2004; Toral et al., 2010). The Sorbonne declaration manifests the European desire to create a Europe of Knowledge. A key factor of this new framework towards which the European universities converge is the Lifelong learning context, and the increasing interest in the "learning to learn" concept. This novel concept tries to replace the idea of defining a fixed time for training by the idea of setting an educational framework in which people turn into students along all their lives. The work market changes so quickly that workers cannot stop to think about their deficiencies in their initial training for the development of their professional career. Conse-

\footnotetext{
* Corresponding author. Tel.: +34 9544812 93; fax: +34 954487373.

E-mail addresses: rmtorres@us.es (M.R. Martínez-Torres), toral@esi.us.es (S.L. Toral), fbarrero@esi.us.es (F. Barrero).
}

quently, education systems must support their graduates with the ability of learning to learn for their whole life (Toral et al., 2006; Durán et al., 2007).

In the recent years, and partly because of this lifelong learning context, the interest in eLearning tools has been increased. These systems allow people for "learning far away", and they have been frequently designed and used in higher education. However, the majority of times their true usage are rarely evaluated following a scientific procedure (Toral et al., 2009). Even when they are evaluated, use evaluation is limited to one-dimensional post-training perceptions of learners (Abdel-Qader et al., 2003), and these perceptions are too often measured using "happy sheets", which ask learners about their satisfaction with the overall learning experience.

In this paper, the Technological Acceptance Model (TAM) is proposed as the starting point in the procedure to evaluate the use of an eLearning tool (Davis, 1989; Davis et al., 1989). In accordance with this model, the true usage an individual makes of the system is driven by the intention of use, which in turn is determined by the perceived usefulness and the perceived ease of use. The perceived usefulness is the extent in which someone believes that using a particular technology will improve his/her performance. The perceived ease of use refers to the degree in which someone believes the use of this technology will not involve a disproportionate effort (Toral et al., 2007a). The intention of use is defined as the degree an individual intends to develop a specific behaviour (Martínez-Torres et al., 2008). The impact of other external variables in the intention of use is always realized in an indirect way across the perceived usefulness or the ease of use (Lee et al., 
2003). This is the reason to identify these three external variables. Nevertheless, only the external meaningful variables must be selected to develop an acceptance model of the tool. The principal problem of TAM rests on the large number of variables which can be a priori presumed meaningful, as well as the number of their associated indicators. Although it is possible to design a model using all the available variables, this solution has many problems. For example, using an excessive number of variables and indicators can lead to an over-dimensioned model, with a high predicted variance (Last et al., 2004). To avoid these problems, it is desirable to remove those variables and indicators which are only slightly important before the modelling process begins. The identification based on the experts' opinion is also a valid alternative which have been used in other studies (Han et al., 1999, 2000). These experts examine the relations between the variables, selecting those which they consider to be more relevant before starting the modelling process (Han et al., 2000). In our study, concept mapping has been used to identify the external variables which are necessary to design an eLearning system for practical and laboratory training in higher education. Concept mapping is a scientific technique which also considers the experts' opinion, but using a combination of statistical treatments to extract the results in terms of maps.

This paper has been organized as follows. First, a brief description on eLearning and its relation to distance learning is presented. Then, the methodology to design an eLearning system is proposed and described. This methodology is applied to a specific subject focused on advanced microprocessors. The obtained results are shown afterwards. Finally, the major conclusions derived from this research are outlined.

\section{E-Learning and the distance learning}

Learning through electronic systems has increased since the development of the first computer (Schodorf et al., 1996; Taylor et al., 2003; Sanchez and Garcia-Rodicio, 2008) or, more recently, since the emergence of Internet. Nowadays, Internet has turned into a real network for the intercommunication worldwide, offering educational services which include virtual laboratories, environments for learning, and distance and asynchronous multimedia courses (Chirico et al., 2005). Multimedia tools, web educational environments, simulation environments, and the distance education have turned into viable educational methodologies, increasing flexibility, accessibility, adaptability, and eliminating the spatial and temporary restrictions of the educational process (Toral et al., 2005).

eLearning is defined as the use of the Information and Communication Technologies (ICT) to improve the quality of learning by facilitating access to resources and services, as well as remote exchanges and collaboration. Students and academics do not have to stay together in the same place, at the same time (Martínez-Torres et al., 2005). eLearning, as the others e-terms, originates as the result of applying ICT to training and learning as a way of study. Also we might find eLearning under the denomination of web based instruction, e-based training, or training online (Lim et al., 2007). All of them are expressions which take to the same idea of a formative process developed in Internet (Littlejohn et al., 2008).

According to Mansur (2000), the possibilities of training distantly arose to respond to important training needs such as: literacy, incorporation to the work environment and population isolated or disabled to move to the centers of conventional studies. Nowadays, it is more difficult for people to take in-place training because of their complex way of life. This leads us thinking on this modality of study (Littlejohn et al., 2008).

The modality of training distantly has passed through different stages over the years. Taking into account different scenarios, we will focused on Tiffi and Rajasingham's categorization (Tiffi and Rajasingham, 1995). First, the traditional distant education was based on courses for correspondence; then the courses were developed through audio-visual means, as the radio or TV. Later, there arose what is known as open education, which was focused on the learning by oneself in centres of study. Finally, the virtual education modality making use of Internet as a training media appeared. The new education and learning environments generated in technological areas turn the real place into a virtual place, and the training process focus is shifted from teachers and contents to students and the construction of their knowledge (Gallardo et al., 2007).

So, which is the difference between virtual modality and distant modality? Is it only by applying ICT? To answer these questions, it is indispensable to remember that students' and academics' roles are changing. Nowadays, not only teaching is talked about, but also learning to learn. It is very important the language and the communication and interaction generated. ICT constitutes a way to make both the academic and the student roles easier. However, a virtual course does not mean reading through a screen, downloading files to study them, or even creating a forum to bring together the contributions of people. It is a question of placing the teaching material inside a course and of being able to handle them in a coherent way (Gallardo et al., 2007).

We propose that the design of a virtual course must be quite similar to a face to face course. In both cases, there must exist suitable planning and training objectives. The difference consists of the paradigm of learning to be taken into account. Most of the time, people have tried to copy what is taught in-place to a virtual course. This is a serious mistake, and the consequence is a disappointment from those who experience these virtual programs (Littlejohn et al., 2008). At university level, the use of ICT should be focused on flexibility and self-management. ICT can clearly improve the potentials of these types of resources, even more if the technological literacy of the students has to be taken into account. The most important thing for an academic is to plan his/her educational action and the use of the ICT in order to develop a teaching model focused on the students requirements. Meanwhile, students should promote these means and resources to be able to develop their learning process in an easier way.

\section{Objective and methodology}

The aim of this research consists of identifying those variables which should be taken into account when designing an eLearning tool, so that students can manage their own learning process easily. The process employed to identify these variables is based on concept mapping techniques (Trochim, 1989). Basically, concept mapping is a form of structured conceptualization which incorporates the opinion of a set of experts. Obtained results can be used to develop a conceptual framework or to guide an evaluation (Vega-Riveros et al., 1998; Hellström and Husted, 2004; Amadieu et al., 2010).

The procedure for developing concept maps includes quantitative and qualitative features. First, the participants are required to generate ideas through a brainstorming session. The selection of participants is one of the most important tasks of the process. In general, the conceptualization process is improved if a wide variety of relevant experts is included. A broad and heterogeneous group of participants ensures the consideration of different points of view will, thus encouraging the "construction" of a right conceptual framework. Then, the obtained information is structured, quantified, and analysed using a double statistical procedure: multidimensional scaling (Rencher, 2002) and cluster analysis (Ward, 1963; Toral et al., 2007b). One of the most interesting advantages 
of concept mapping is its ability to mathematically reveal the main categories of ideas obtained from the participants' input information. Each categorization of ideas is represented in a cluster form on a final map. The proximity between clusters means that they are more directly linked. Notice that maps summarize the opinions of the participants, but the statistical treatment guarantees that no opinion prevails upon another. The procedure to develop concept mapping considers the following stages (Kolb and Shepherd, 1997):

1. Selection and preparation of the participants.

2. Brainstorming of statements related to the focus matter.

3. Structuration (sorting and rating) of the statements.

4. Representation of the statements on a point and cluster map (using the double statistical treatment).

5. Interpretation of the resulting maps.

The aim of the statistical treatment is to summarize the opinions as a set of clusters or categories, making cluster analysis a critical point of the proposed methodology.

There are two major methods of clustering: hierarchical and partitioning algorithms. In hierarchical clustering, the data are not partitioned into a particular cluster in a single step. Instead, a series of partitions takes place, which may run from a single cluster containing all objects to $n$ clusters, each one containing a single object. Hierarchical clustering can be subdivided into agglomerative methods, which proceed by series of fusions of the $n$ objects into groups, and splitting methods, which successively separate $n$ objects into finer groups. In both cases, once objects are assigned to clusters, this assignment cannot be changed later. Partitioning algorithms try to minimize a given clustering criterion by iteratively relocating objects between clusters until a (locally) optimal partition is attained. The main advantage of partitioning algorithms is its ability to change objects assignment to groups during the application of the algorithm. The main drawback is that achieving a global minimum is not guaranteed (Basu et al., 2009).

As concept maps are usually intended for exploratory analysis where prior knowledge is scarce, an agglomerative hierarchical algorithm is chosen to perform the cluster map (Trochim, 1989; Katsanos et al., 2008). The algorithm consists of the following steps:

1. Select the finest partition.

2. Compute the distance matrix $\rho$. DO

3. Find those two clusters with the closest distance.

4. Merge together those two clusters.

5. Compute a distance between the new resulting groups obtaining a reduced distance matrix $D$.

UNTIL all clusters are agglomerated into $\chi$

Whenever two objects, $A$ and $B$, are united, the distance between this new group $A+B$ and group $S$ should be evaluated using the following distance function:

$$
\begin{aligned}
d(S, A+B)= & \delta_{1} d(S, A)+\delta_{2} d(S, B)+\delta_{3} d(A, B) \\
& +\delta_{4}|d(S, A)-d(S, B)|
\end{aligned}
$$

where $\delta_{j}$ s are weighting factors that depends on the particular chosen agglomerative algorithm. In the case of Ward algorithm, they are defined as follows:

$\delta_{1}=\frac{n_{S}+n_{A}}{n_{S}+n_{A}+n_{B}}$
$\delta_{2}=\frac{n_{S}+n_{B}}{n_{S}+n_{A}+n_{B}}, \delta_{3}=\frac{n_{S}}{n_{S}+n_{A}+n_{B}}, \delta_{4}=0$

where $n_{A}=\sum_{i=1}^{n} I\left(x_{i} \in A\right), n_{B}=\sum_{i=1}^{n} I\left(x_{i} \in B\right), n_{S}=\sum_{i=1}^{n} I\left(x_{i} \in S\right)$ are the number of objects in groups $A, B$ and $S$, respectively.

As a difference to other agglomerative techniques, Ward's method joins together the two groups that minimise the error sum of squares (i.e. the within-cluster sum of squares). It produces spherical clusters with similar sizes. This is exactly one of the aims of this technique: to avoid a drastic increment in a particular cluster, obtaining groups as homogeneous as possible.

The inertia inside a group is used as a measure of heterogeneity. The inertia of a group $S$ is defined as follows:

$I_{S}=\frac{1}{n_{S}} \sum_{i=1}^{n_{S}} d^{2}\left(x_{i}, \bar{x}_{S}\right)$

Being $\bar{x}_{S}$ the centre of gravity over the groups. $I_{S}$ represents a measurement of the dispersion of the group around its centre of gravity. Using Euclidean distance, $I_{S}$ is obtained as the sum of the variances of the $p$ components of $x_{i}$ inside group $S$.

Whenever two objects $A$ and $B$ are joined together, a larger inertia value $I_{A+B}$ of the new group $A+B$ is obtained. The increment of the inertia value is given by Eq. (3).

$\Delta(A, B)=\frac{n_{A} n_{B}}{n_{A}+n_{B}} d^{2}(A, B)$

Those groups with the smallest increase in $\Delta(A, B)$ are merged together. In summary, Ward algorithm is similar to the centroid algorithm, but using an inertial distance instead of a geometric distance.

\section{Results}

A web-based environment which provides access for remote control of Digital Signal Processors (DSP device) and real instrumentation has been considered in this study. A real lab test bench, consisting of an oscilloscope, a power supply, an arbitrary waveform generator, and a Digital Signal Processor board, can be remotely accessed and managed using virtual instruments created with LabVIEW (Barrero et al., 2008). Therefore, real lab exercises can be remotely developed avoiding spatial and temporal restrictions of physical labs.

\subsection{Selection and preparation of the participants}

People who took part in the research were related to university education, with a wide experience in eLearning tools. The reason for this choice was twofold:

1. To rely on people able to show the reality of the University. Borrowing a generic existing model from the literature is always possible. However, this model would not be consistent to the situation or to the current needs of the Universities, remaining far from their requirements. That is the reason why concept mapping considers participants with a direct link to the problem or question to be solved.

2. To rely on people who have different points of view when designing eLearning systems.

Finally, 14 participants took part in the sessions. They include lecturers directly involved with the proposed eLearning system, lecturers with knowledge about Digital Signal Processors, students, experts in the design of eLearning systems and tools, and experts from electronic companies. The number of 14 participants agrees with the adequate limits of ten and twenty established by Kolb and Shepherd (Kolb and Shepherd, 1997). 


\subsection{Brainstorming of statements}

The brainstorming focus was: "Please, identify all those things which should be taken into account to design an eLearning tool to be applied to practical and laboratory training. Remember that these things should have some influence over the utility and the perceived facility of use of the eLearning tool in a major or minor degree". Seventy-seven statements were identified in this session. All of them are listed in Appendix A.

\subsection{Structuration of the statements}

The aim of this second session consists of sorting and rating those statements identified in the previous session, which describes the conceptual domain of the chosen topic.

Therefore, a questionnaire was made to structure the 77 identified statements. This questionnaire was divided in two parts. The first one referred to sorting the statements. Participants must sort the generated statements into homogeneous groups by applying their previous experience, and then they must choose a name for each group. A binary individual similarity matrix $S$ of $n \times n$ dimension is obtained from each questionnaire, considering that a value of 1 in the $(i, j)$ position means that the $i$ th and $j$ th items have been grouped together, and 0 otherwise. Participants were required to locate each item in just one group. They were also encouraged to be imaginative, so the final sorting results lead to certain diversity (all the items could not be grouped in just one category nor obtaining a number of categories equal to the number of starting statements). Participants could freely decide the number of groups. The total similarity matrix $T$ of $n \times n$ dimension is obtained summing all the similarity matrices.

The second part of the questionnaire involved rating each statement. Participants were asked to rate the statements in a Likerttype response scale, with a range of $1-7$, to indicate their contribution to the final objective of concept mapping. It was considered $1=$ "little contribution", 7 = "big contribution", and the numbers in between referred to intermediate contributions. A "zero contribution" value was not possible, since the brainstorming session specifically asked for those statements which should "have some influence over the utility and the perceived facility of use of the eLearning tool in major or minor degree".

\subsection{Representation of items in a concept map}

A double statistical treatment, consisting of a multidimensional scaling analysis and a cluster analysis, was applied to the collected data.

First, a multidimensional scaling analysis was used to visualize the 77 statements in a two-dimensional map so that the distance between the different points or statements is related to their affinity or similarity. Those points or statements located closer to each other are conceptually more similar than those located further away. Multidimensional scaling is a mathematical tool that pictures the structure of a set of objects from data that approximate the distances between pairs of the objects. The data must express the amount of similarity, dissimilarity, distance, or proximity between pairs of objects.

The objective of multidimensional scale is to find the coordinates of points in multidimensional space. Each object is represented by a point in this multidimensional space, and the points are arranged in this space so that the distances between pairs of points have the strongest possible relation to the similarities among the pairs of objects (Fahrmeir and Hamerle, 1984). Consequently, two similar objects are represented by two points that are close together, while two dissimilar objects are represented by two points that are far apart. The space is usually a two- or three-dimensional Euclidean space, but may be non-Euclidean and may have more dimensions. In the particular case of a twodimensional solution, the set of points are placed on a plane, and the analyst is responsible of an adequate interpretation of the obtained dimensions. Due to the difficulties of interpreting solution with more than three dimensions, two dimensional graphs are usually used when working with concepts maps.

The obtained results through multidimensional scaling lead to a point map representing the set of statements obtained during the brainstorming session (Fig. 1). Each point labelled with a number represents one of the identified items listed in Appendix A. Distances among points are obtained using a multidimensional scaling, which is applied to the total similarity matrix obtained

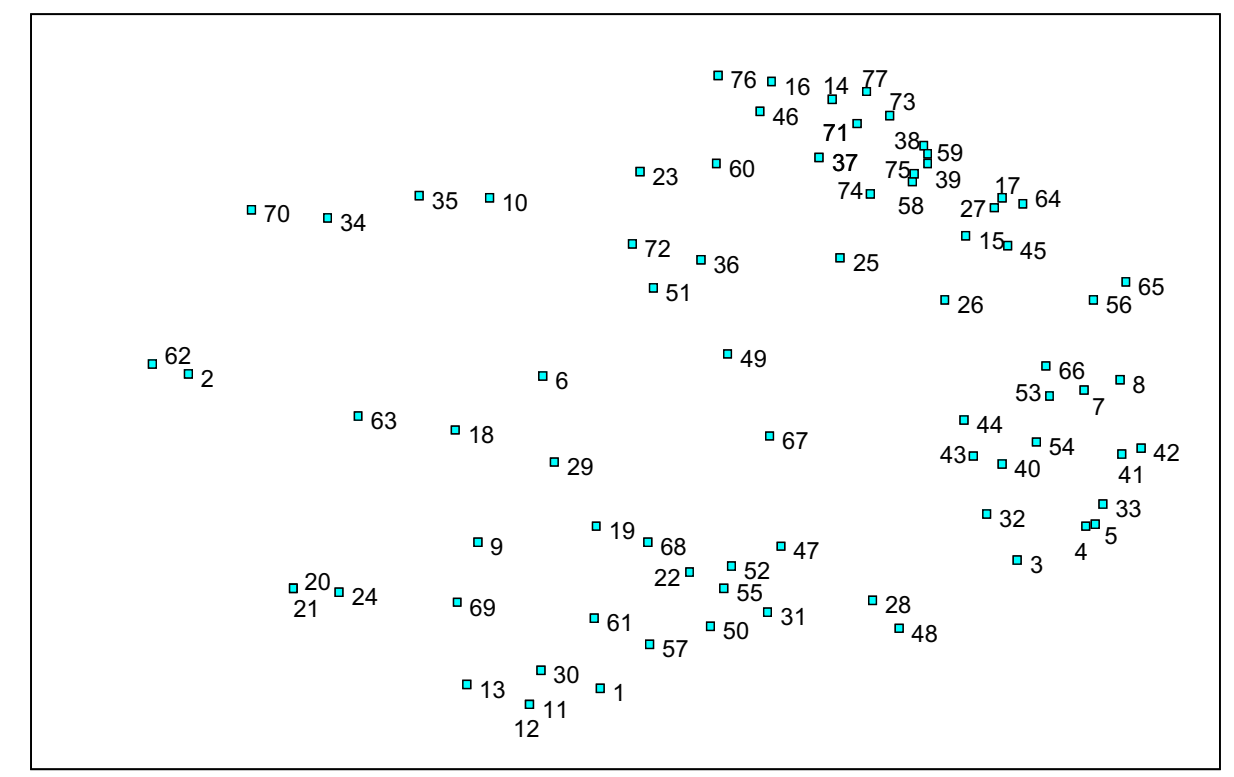

Fig. 1. Point map. 
during the sorting stage. The final coordinates of each point are calculated through an iterative process, being the most common approach the algorithm referred as the Shepard-Kruskal algorithm (Fahrmeir and Hamerle, 1984). The point rating map, illustrated by Fig. 2, includes the ratings provided by participants. Multi-layered squares refer to the mean rating of the identified statements.

Second, a cluster analysis was made using the point map (Everitt, 1993). The cluster analysis organises the information in homogeneous groups of concepts. These groups were taken from the point set of the multidimensional scaling analysis. Ward's algorithm was also selected because offers more sensitive results that can be easily interpreted and leads to more homogeneous resulting groups (Ward, 1963). Initially, each item is considered as a separate cluster, obtaining a solution with n clusters ( 77 in this study). From this initial solution, Ward's algorithm merges iteratively those clusters minimizing the sum of squared errors. An important issue is determining the number of clusters in the final solution. In general, the analyst is responsible of choosing a final number of clusters so that the statements integrating each cluster conform a homogeneous meaning. As a general rule, it is preferred to err by excess than by defect, and it is preferable a high number of clusters than grouping heterogeneous concepts inside only one cluster (Toral et al., 2007c).

A cluster map (Fig. 3) and a cluster rating map (Fig. 4) were obtained. These maps represent the items to be taken in mind when designing an eLearning system. Cluster layers are obtained as the average rating of the clustered statements (the range of values for each layer is shown on bottom left corner of the figure). It is assumed a certain loss of information by representing the results in a two-dimensional space in order to facilitate the interpretation of

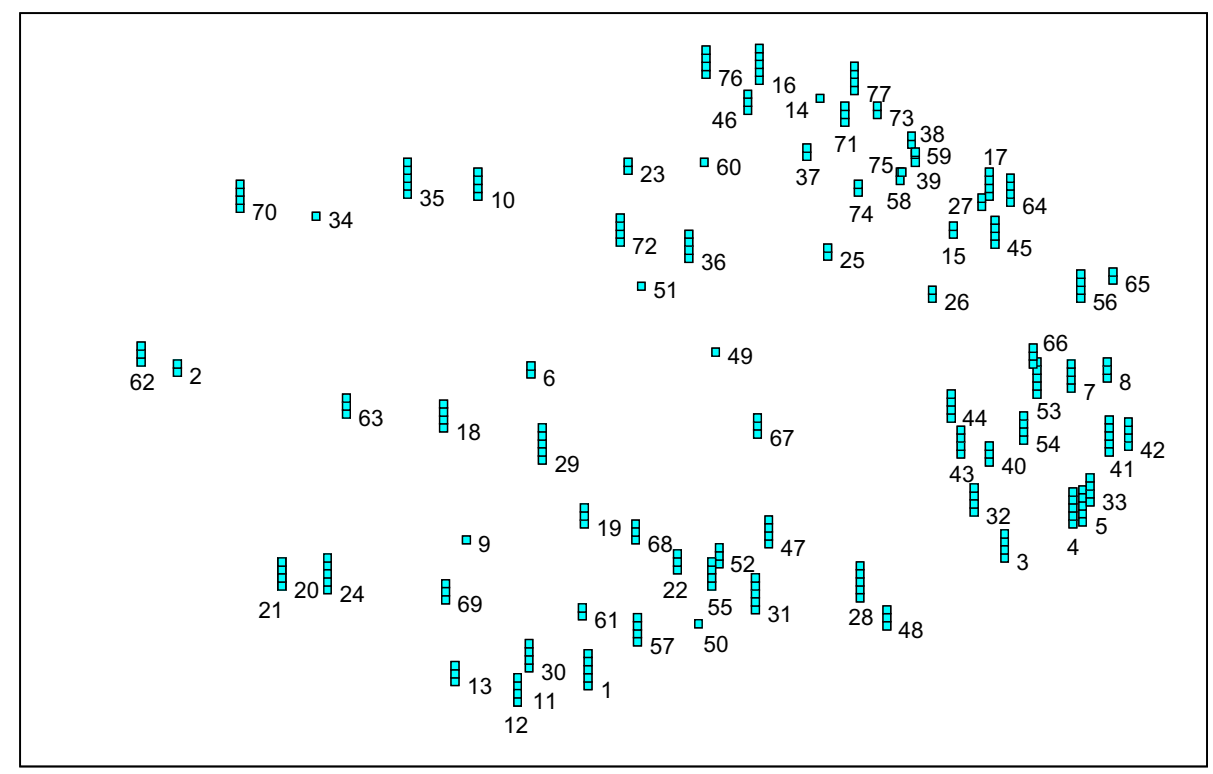

Fig. 2. Rated point map.

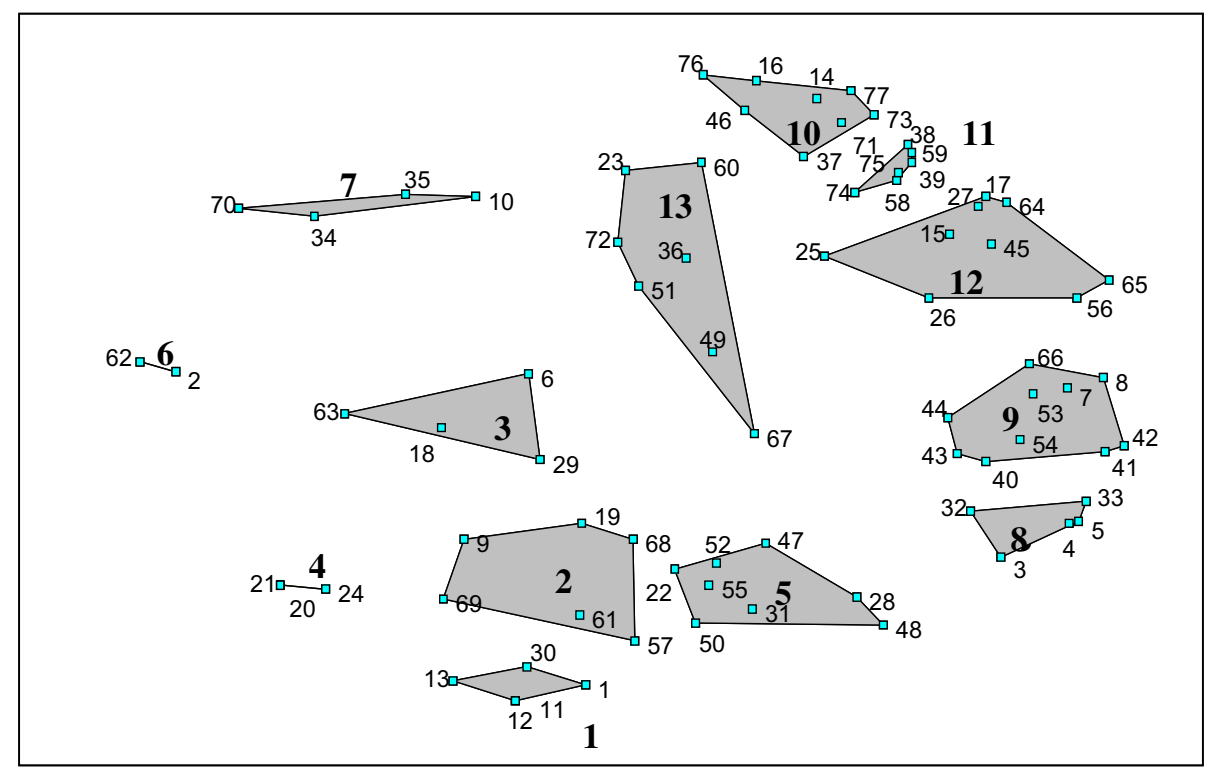

Fig. 3. Clusters map. 


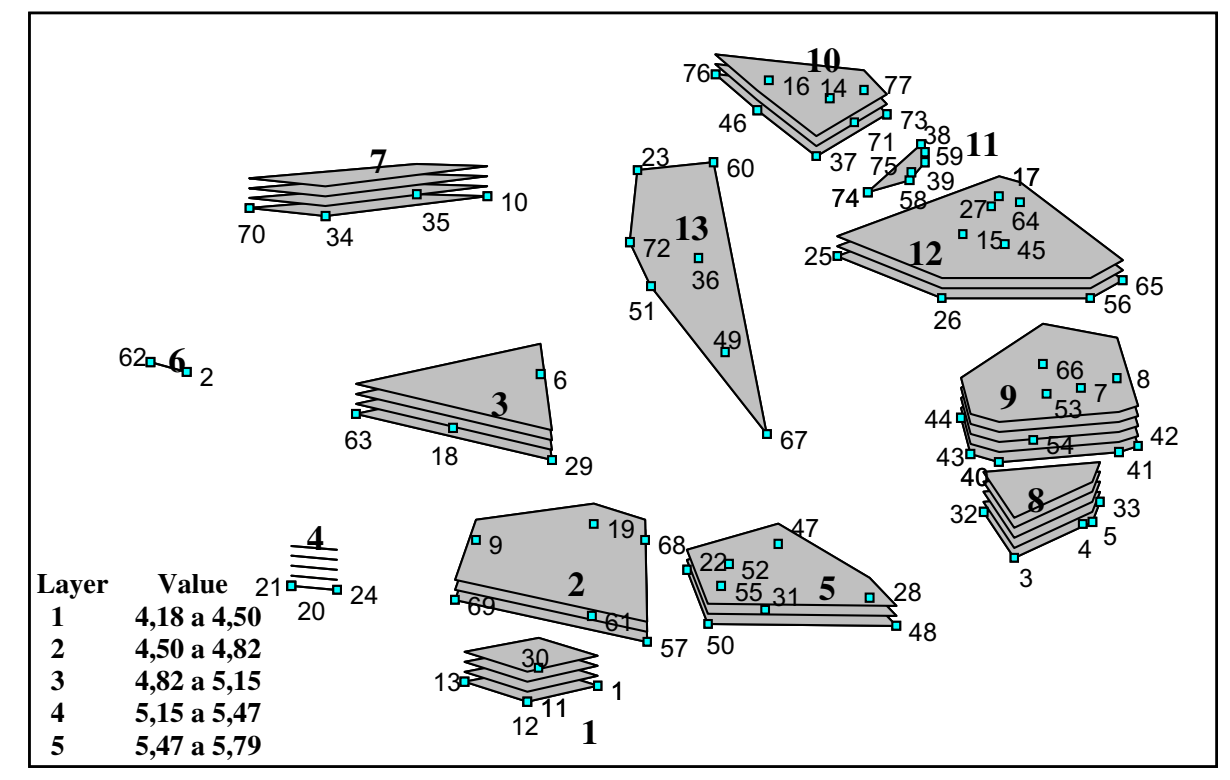

Fig. 4. Rated clusters map.

maps. The number of obtained clusters is thirteen. This number of clusters has been obtained as an iterative process, beginning with a high number of clusters and stopping when the homogeneity of a cluster is lost.

\subsection{Interpretation of the maps}

Four different types of maps have been obtained from concept mapping: the point map, the rated point map, the cluster map and the rated cluster map. Generally, the results obtained from cluster analysis are more difficult to interpret than those obtained from the multidimensional scaling analysis. The analyst should maintain the integrity of the provided results by the multidimensional scaling; that is to say, to achieve a solution that will not allow the clusters to overlap.

Table 1 shows the name of the 13 clusters, which can be grouped into four major regions, as it is shown in Fig. 5.

The first major region, placed on the bottom of the map (Fig. 5), aggregates several issues related to the Teaching methodology. It includes four clusters:

- Cluster 1: Format. This refers to the external appearance of the eLearning tool. It must be adapted to users' training. If there are some similarities among this format and traditional lectures, the skills developed through the latter will be also developed through the eLearning tool. Therefore, this similarity is especially desirable.

- Cluster 2: Methodology. This refers to the fact that the design of the eLearning tool has to be adapted to its environment (it has to be suitable to the topic or the subject to be learned). Therefore, the scope of the tool and its objectives have to be clearly defined, encouraging team-work.

- Cluster 4: Feedback. This refers to the degree the students know how well they are performing, and whether their performance is improving, deteriorating or remaining constant.

- Cluster 5: User adaptation. This refers to the capacity of the eLearning tool to integrate different learning methodologies, according to the needs of the users. From a constructivist view, it must allow the navigation along the system, providing an individualized environment for the user. From the cognostivist view, it has to offer practices and examples based on actual
Table 1

Name of clusters.

\begin{tabular}{|c|c|c|c|}
\hline Name of clusters & & & Mean \\
\hline \multirow{4}{*}{$\begin{array}{l}\text { Region 1: } \\
\text { teaching } \\
\text { methodology }\end{array}$} & Cluster 1 & Format & 5,27 \\
\hline & Cluster 2 & Methodology & 4,91 \\
\hline & Cluster 4 & Feedback & 5,49 \\
\hline & Cluster 5 & User adaptation & 4,89 \\
\hline \multirow{3}{*}{$\begin{array}{l}\text { Region 2: social } \\
\quad \text { view }\end{array}$} & Cluster 3 & Communicativeness & 5,21 \\
\hline & Cluster 6 & Diffusion & 4,23 \\
\hline & Cluster 7 & Accessibility & 5,38 \\
\hline \multirow{4}{*}{$\begin{array}{l}\text { Region 3: internal } \\
\text { features }\end{array}$} & Cluster 10 & Reliability & 5,11 \\
\hline & Cluster 11 & $\begin{array}{l}\text { System } \\
\text { management }\end{array}$ & 4,44 \\
\hline & Cluster 12 & User tools & 5,07 \\
\hline & Cluster 13 & $\begin{array}{l}\text { Learning } \\
\text { management }\end{array}$ & 4,20 \\
\hline \multirow[t]{2}{*}{$\begin{array}{l}\text { Region 4: user's } \\
\quad \text { motivation }\end{array}$} & Cluster 8 & $\begin{array}{l}\text { Interactivity and } \\
\text { control }\end{array}$ & 5,79 \\
\hline & Cluster 9 & $\begin{array}{l}\text { Enjoyment and } \\
\text { playfulness }\end{array}$ & 5,51 \\
\hline
\end{tabular}

events, allowing the user to solve problems. Finally, from a behavioral view, it has to allow the user to monitoring and controlling the activity.

- As we move counter-clockwise on the map, the second major region represents the Social perspective of the tool. It groups three clusters:

- Cluster 3: Communicativeness. This refers to the capacity of the tool to transfer understanding of meaning among users, and between the student and the teacher, creating a real community of learning.

- Cluster 6: Diffusion. This refers to the fact that the diffusion of the eLearning tool, and the knowledge of it by the users, encourages its use.

- Cluster 7: Accessibility. This refers to the channel used to accessing the eLearning tool. It should be easy and universally known. 


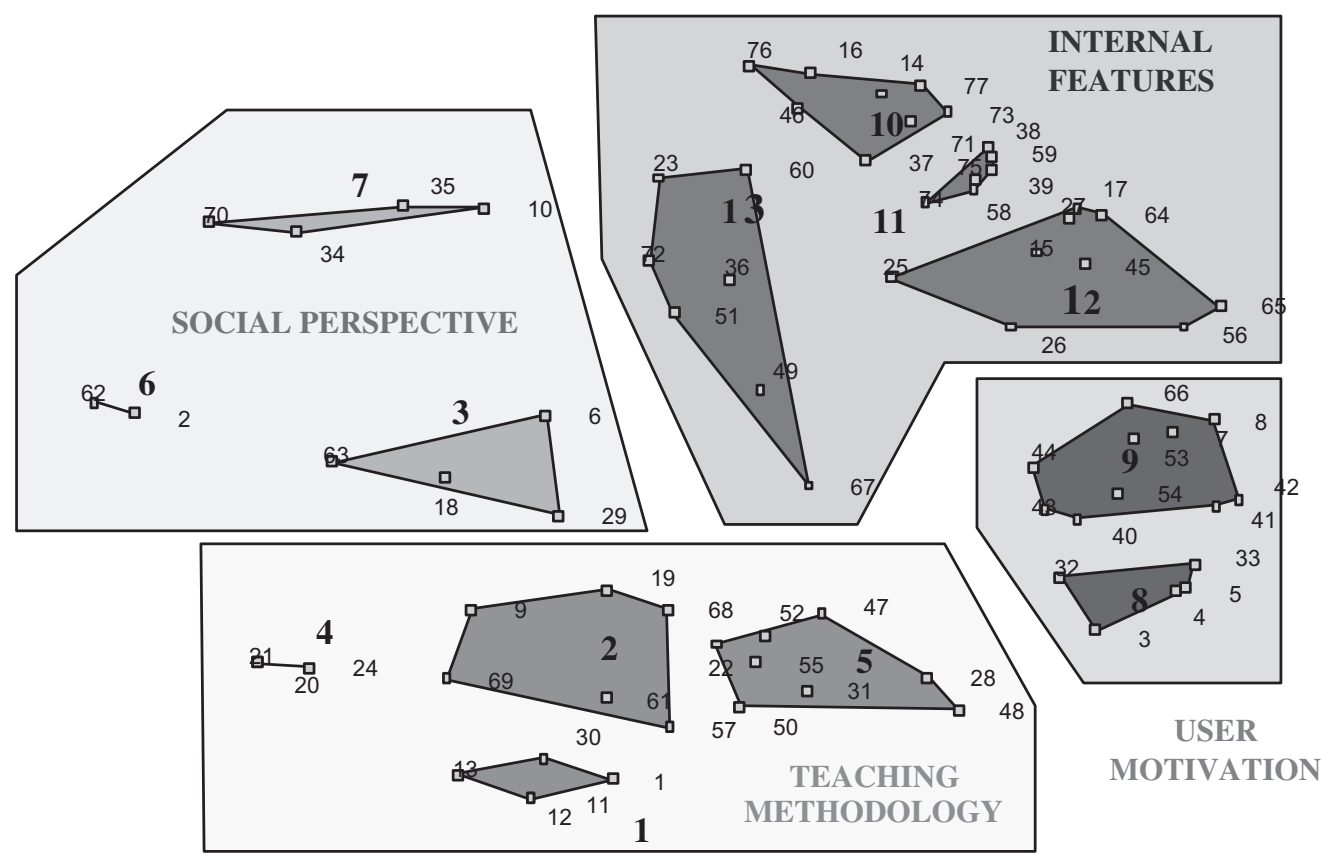

Fig. 5. Areas in the cluster map.

The third region of the map is the most relevant for the internal features of the eLearning tool. It groups four clusters:

- Cluster 10: Reliability. This refers to the fact that the tool has to be designed using criteria of strength, stability and safety. Data should also be able to be exported and imported in a variety of different formats.

- Cluster 11: System management. This refers to those additional features which allows the instructor to monitor and send instructions to manage and direct the eLearning resources, for example, statistical tools, number of connected users, analysis data tools, .

- Cluster 12: User tools. This refers to the features and contents of the eLearning tool, which have to be suitable for the subject to be learned. The user should be able to look up, to take part actively in the learning, to take up the learning, to export data to take part in forums, etc.

- Cluster 13: Learning management. This refers to the features which allow monitoring the students' performance when navigating through the eLearning tool, registering their activity and monitoring their improvement.

The last major region pertains most on the users' motivation on the tool. It groups 2 clusters:

- Cluster 8: Interactivity and control. Interactivity refers to the degree in which technology allows or supports the interaction between the user and the system. Control refers to the capacity of the user to decide the speed and the arrangement of learning, to select the content, and to repeat or check past contents.

- Cluster 9: Enjoyment and playfulness. The eLearning tool must offer an attractive and friendly environment, similar to known environments. The graphical design should be attractive, the language should be easy to understand, and the help option should allow the user to easily solve any problem.

The clusters with lower rating are Clusters 6, 11 and 13 (see Fig. 4). They are referred to Diffusion, System management and
Learning management, respectively. It could be said that Cluster 6 receives a low rating because the eLearning tool is usually embedded in a subject without extra diffusion necessity. However, Clusters 11 and 13 refer to internal features which do not have a direct influence on the students' use of the tool, since they do not perceive their existence. The rest of clusters receive a similar rating, though stands out specially Cluster 8 (Interactivity and control) and Cluster 9 (enjoyment and playfulness).

Other interesting result extracted from the analysis of the maps refers to the possibility of managing the eLearning tool. Only through planning, organizing, leading and controlling, students can efficiently manage the eLearning tool (Mintzberg, 1973). Planning is included in Cluster 2, "Methodology". It is necessary to set objectives and to decide which activities are needed to achieve them. Organizing is developed through Clusters 5 (User adaptation); Cluster 7 (Accessibility) and Cluster 12 (User tool). Consequently, once the objectives are established, the next step would fix the tasks to be done, as well as when, how and who will do them. Leading can be seen in Cluster 1 (Format), Cluster 3 (Communicativeness), Cluster 6 (Diffusion), Cluster 9 (Enjoyment and playfulness), and Cluster 10 (Reliability). It is then necessary to influence the behaviour of the potential user, so the eLearning tool should have an attractive, known, friendly and reliable design. Finally, controlling is carried out in Cluster 4 (Feedback), Cluster 11 (System management), and Cluster 13 (Learning management). The eLearning tool should have mechanisms of feedback in order to know how well the user's performance is.

\section{Reliability analysis}

The traditional theory about reliability that is normally applied to social science research does not correctly fit on concept maps. Reliability is an expression of the proportion of the variation among scores that are due to object of measure. As variation due to error goes to zero, the reliability of an assessment goes to 1 . However, this definition assumes there is a right an- 
swer previously known for each item (Traub, 1994). In the context of a rating situation, reliability refers to the degree to which the ratings are free from inconsistencies. Ratings are subject to multiple sources of inconsistencies including: (a) differences between two or more raters who rated the same map on the same rating occasion (i.e., a lack of inter-rater reliability), and (b) differences in ratings from any given rater who rated the same map on two or more rating occasions (i.e., a lack of intrarater reliability). In addition, to these two common types of rater inconsistencies, other inconsistencies may involve various kinds of two-way interactions such as rater-by-occasion interaction. That is the reason why concept mapping reliability is focused on consistency using groups of supposedly homogeneous participants. Therefore, the reliability of the similarity matrix or the reliability of the map is calculated instead of the reliability of particular items (Trochim, 1993). In accordance with the study by Trochim (1993), the reliability of concept mapping may be tested using six coefficients that can be estimated from the available data. In this study, 38 projects were evaluated, extracting several statistical values related to the six coefficients considered. In general, a concept mapping can be considered reliable if the values of these coefficients are between the standard values defined in Table 2 . The coefficients defined by Trochim are next detailed:

1. Individual-to-Individual Sort Reliability $\left(r_{\mathrm{II}}\right)$ : this coefficient correlates each person's binary sort matrix, $S_{n \times n}$, for each pair of individuals; it measures the degree of sorting correlation among the individual sorting carried out by participants in the development of the concept map. This coefficient is calculated as the average of the correlations, and by applying the Spearman-Brown Prophecy formula (Nunnally, 1978).

$$
r_{k k}=\frac{k \bar{r}_{i j}}{1+(k+1) \bar{r}_{i j}}
$$

where $r_{i j}$ is the estimated correlation, $k$ the $N / n$, being $N$ is the total sample size and $n$ is the sample size on which $r_{i j}$ is based and $r_{k k}$ is the estimated reliability according to the Spearmen Brown Prophecy formula:

2. Individual-to-Total Matrix Reliability $\left(r_{\mathrm{IT}}\right)$ : this index correlates each person's binary sort matrix $S_{n \times n}$, with the total matrix $T_{n \times n}$; it explains the correlation between individual and group sorting. The same than the previous coefficient, it is calculated as the average of these correlations, including also the Spearmen Brown Prophecy formula.

3. Individual-to-Map Reliability $\left(r_{\mathrm{IM}}\right)$ : it measures the correlation of each person's binary sort matrix, $S_{n \times n}$, with the Euclidean matrix distances, $D_{n \times n}$, which is obtained from multidimensional scaling as the distance matrix among individual items.

Table 2

Descriptive statistics for reliability estimation.

\begin{tabular}{lllllll}
\hline & $r_{\mathrm{II}}$ & $r_{\mathrm{IT}}$ & $r_{\mathrm{IM}}$ & $r_{\mathrm{RR}}$ & $r_{\mathrm{SHT}}$ & $r_{\mathrm{SHM}}$ \\
\hline $\begin{array}{c}\text { Number of } \\
\text { projects }\end{array}$ & 33 & 33 & 33 & 37 & 33 & 33 \\
Mean & 0.81507 & 0.92965 & 0.86371 & 0.78374 & 0.83330 & 0.55172 \\
Median & 0.82060 & 0.93070 & 0.86280 & 0.82120 & 0.84888 & 0.55881 \\
Minimum & 0.67040 & 0.88230 & 0.74030 & 0.42700 & 0.72493 & 0.25948 \\
Maximum & 0.93400 & 0.97370 & 0.95490 & 0.93540 & 0.93269 & 0.90722 \\
SD & 0.07016 & 0.02207 & 0.04771 & 0.12125 & 0.05485 & 0.15579 \\
eLearning & 0.73399 & 0.92615 & 0.87592 & 0.7785 & 0.90652 & 0.83778 \\
\hline
\end{tabular}

Again, the average value of these correlations is obtained using the Spearmen Brown Prophecy formula.

4. Average Inter-Sort Reliability $\left(r_{\mathrm{RR}}\right)$ : it is calculated as the average correlation among the scores of each pair of persons (including the Spearmen Brown Prophecy formula).

5. Split-Half Reliabilities $\left(r_{\mathrm{SHT}}\right.$ and $\left.r_{\mathrm{SHM}}\right)$ : in this case, the set of sorts from each project is divided into two halves, $A$ and $B$. A separate concept mapping is solved for each group. The correlation among their total similarity matrices, $T_{\mathrm{A}}$ and $T_{\mathrm{B}}$, is evaluated, and then the Spearmen Brown Prophecy formula is applied to obtain $r_{\mathrm{SHT}}$. The Euclidean distances matrices $D_{\mathrm{A}}$ and $D_{\mathrm{B}}$, obtained from separate multidimensional scaling, are also correlated, and the Spearmen Brown correction is applied to obtain $r_{\mathrm{SHM}}$.

Notice that the values of these six coefficients in our particular case rely on the acceptable levels defined in the Trochim's study (see Table 2).

\section{Conclusions}

The recent development of ICT systems allows new research fields related to the improvements in the teaching methodologies, and new ways for accessing knowledge. New training behaviour, such as "distance learning" with support of the ICT, are being studied in order to facilitate training.

The objective of this study consists of identifying a set of external variables that should be taken into account prior to the design of an eLearning system for practical and laboratory training, using a scientific method called concept mapping. The accuracy of the technique has been confirmed through a reliability analysis. Obtained results, which could be extended to other eLearning systems, show that external variables can be grouped into four different areas: teaching methodology, social perspective, user's motivation, and internal features.

Teaching methodology and social perspective constitutes generic features of any eLearning system. On one hand, the system must offer pacing learning at the Individual's level, providing a user friendly format and feedback for guarantying users can control and evaluate their learning activities. On the other hand, accessibility and a fluent communication among users, and among teacher and users, should also be considered to overcome temporal and spatial distance.

User's motivation and internal features constitutes specific characteristics of practical and lab training. Among the internal features, reliability and user tools are quite important for lab teaching. Notice that the eLearning tool must remotely control instrumentation equipments, as well as an electronic board where the students must test and check their self-developed programs. Therefore, the eLearning system must support a trial and error iterative process until the exercise is successfully completed. Besides, students must feel the sensation of operating with real instrumentation equipments, despite the fact of being using virtual instruments. Finally, user motivation is especially important when dealing with lab training because the degree of interactivity is much higher than in a theoretical learning, and students must be encouraged to give an additional effort to work with the eLearning environment.

\section{Appendix A}

See Table A1. 
Table A1

Brainstorming statements.

\begin{tabular}{|c|c|}
\hline \multicolumn{2}{|l|}{ Statements } \\
\hline 1. Appropriate content for the subject & 40. Playfulness features \\
\hline 2. Student previous requirements to access the tool & 41. Friendly environment \\
\hline 3. Flexible access to contents & 42. Attractive graphic design \\
\hline 4. Easy location of resources & 43. Avoiding initial fear \\
\hline 5. Easy of use & 44. Simple language \\
\hline 6. Integration in the general eLearning framework of the institution & 45. Speed requirements \\
\hline 7. Similarity with previously known framework (windows, menus, ...) & 46. Reasonable cost of the tool \\
\hline 8. Mixture of hypermedia content & 47. Student control of learning pace \\
\hline 9. Definition of the framework of the eLearning tool (remote and/or virtual) & 48. Promotion of student initiatives \\
\hline 10. Universal accessibility to the tool & 49. Internationalization of the tool \\
\hline 11. Similarity to real practical environments & 50. Multidisciplinary features of the content \\
\hline 12. Similarity to face to face education & 51. languages \\
\hline 13. Development of the same skills than the obtained with face to face education & 52. Different levels of complexity \\
\hline 14. Portability to other environments & 53. On line help \\
\hline 15. of different roles (teacher, student, system manager, tutor) & 54. Help structured in several levels \\
\hline 16. Stability/robustness of the system & 55. Learning organization in sequence \\
\hline 17. Technical support provided (e-mail, telephone, forums, ...) & 56. Possibility of resuming an initiated task \\
\hline 18. Inter-personal and inter-role communication & 57. Appropriate length of the offered contents \\
\hline 19. Collaboration and teamwork promotion & 58. Inclusion of additional tools for processing/analysis/generation of results \\
\hline 20. Self-assessment & 59. Implementation of statistical tools for the System management \\
\hline 21. Possibility if a continuous assessment of students & 60. Tools for log analysis \\
\hline 22. Student learning management & 61. Possibilities of mixing different teaching methodologies \\
\hline 23. Student activity recording & 62. Appropriate diffusion of the tool \\
\hline 24. Clear adaptation to the assessment criterions of the subject & 63. Visual feedback (i.e. web-cam) \\
\hline 25. Easy content management by the lecturer & 64. Possibility of exporting data \\
\hline 26. Adaptation to standards(i.e., scorm) & 65. Implementation of a search tool \\
\hline 27. Event management features & 66. Inclusion of a visible student logbook \\
\hline 28. Learning facilities & 67. Auto test generation \\
\hline 29. Perception of the benefits associated to the use of the tool & 68. Generation of different individual task or work \\
\hline 30. Linking the use of the tool with the achievements of competences & 69. Coordination of remote work with face to face lectures \\
\hline 31. Adaptation of the content to different student profiles & 70. Extent of acceptation of the tool among lecturers \\
\hline 32. Interactivity promotion & 71. Security of the tool \\
\hline 33. Control perception of the tool & 72. Accessibility of the tool to people with physical disabilities \\
\hline 34. Student digital literacy & 73. Physical scalable architecture of the tool \\
\hline 35. Student easy of access to the tool & 74. Access time management for students' connections \\
\hline 36. Adaptation to the communication channel & 75. Management of students' connections \\
\hline 37. Possibilities of working off-line & 76. Reliability/accuracy of the tool \\
\hline 38. Maintenance facilities & 77. Security of the stored data \\
\hline 39. Multi-user management features & \\
\hline
\end{tabular}

\section{References}

Abdel-Qader, I.M., Bazuin, B.J., Mousavinezhad, H.S., Patrick, J.K., 2003. Real-time digital signal processing in the undergraduate curriculum. IEEE Transactions on Education 46 (1), 95-101.

Amadieu, F., Tricot, A., Mariné, C., 2010. Interaction between prior knowledge and concept-map structure on hypertext comprehension, coherence of reading orders and disorientation. Interacting with Computers 22 (2), 88-97.

Barrero, F., Toral, S.L., Gallardo, S., 2008. EDSPLAB: remote laboratory for experiments on DSP applications. Internet Research 18 (1), 79-92.

Basu, S., Davidson, I., Wagstaff, K., 2009. Constrained Clustering: Advances in Algorithms, Theory, and Applications, CRC Press, NW.

Chirico, M., Scapolla, A.M., Bagnasco, A., 2005. A new and open model to share laboratories on the Internet. IEEE Transactions on Instrumentation and Measurement 54 (3), 1111-1117.

Davis, F.D., 1989. Perceived usefulness, perceived ease of use, and user acceptance of information technology. MIS Quarterly 13, 319-339.

Davis, F.D., Bagozzi, R.P., Warshaw, P.R., 1989. User acceptance of computer technology: a comparison of two theoretical models. Management Science 35, 982-1002.

Durán, M.J., Gallardo, S., Toral, S.L., Martínez-Torres, M.R., Barrero, F., 2007. A learning methodology using matlab/simulink for undergraduated electrical engineering courses attending to learner satisfaction outcomes. International Journal of Technology and Design Education 17 (1), 55-73.

Everitt, B.S. 1993. Cluster Analysis, Halsted Press.

Fahrmeir, L., Hamerle, A. 1984. Multivariate Statistische Verfahren, De Gruyter, Berlin.

Gallardo, S., Barrero, F., Martínez-Torres, M.R., Toral, S.L., Durán, M.J., 2007. Addressing learner satisfaction outcomes in electronic instrumentation and measurement laboratory course organization. IEEE Transactions on Education $50(2), 129-136$

Hagen, R., 2002. Globalization, university transformation and economic regeneration. International Journal of Public Sector Management 15 (3), 204218

Han, S.H., Kim, K., Yun, M.H., Kwahk, J., Hong, S.W., Han, S., 1999. Usability prediction models based on human product interface elements. In: Proceedings of the 14th Annual International Occupational Ergonomics and Safety Conference, Orlando, FL, USA, pp. 225-230.

Han, S.H., Yun, M.H., Kim, K., Kwahk, J., 2000. Evaluation of product usability: development and validation of usability dimensions and design elements based on empirical models. International Journal of Industrial Ergonomics 26, 477488.

Hellström, T., Husted, K., 2004. Mapping knowledge and IC in academic environments. A focus group study. Journal of IC 5 (1), 165-180.

Joint Declaration of the European Ministers of Education, 1999. The European Higher Education Area - Bologna Declaration, Bologna, June 19, 1999.

Katsanos, C., Tselios, N., Avouris, N., 2008. Automated semantic elaboration of web site information architecture. Interacting with Computers 20 (6), 535-544.

Kolb, D.G., Shepherd, D.M., 1997. Concept mapping organizational cultures. Journal of Management Inquiry 6 (4), 282-295.

Last, M., Abraham, K., Bunke, H., 2004. Artificial Intelligence Methods in Software Testing. Series in Machine Perception Artificial Intelligence, World Scientific Publishing Co., UK.

Lee, Y., Kozar, K.A., Larsen, K.R.T., 2003. The technology acceptance model: past, present, and future. Communications of the Association for Information Systems 12 (50), 752-780.

Lim, H., Lee, S.-G., Nam, K., 2007. Validating E-learning factors affecting training effectiveness. International Journal of Information Management 27, 22-35.

Littlejohn, A., Falconer, I., Mcgill, L., 2008. Characterising effective eLearning resources. Computers \& Education 50 (3), 757-771.

Mansur, A., 2000. La gestión en la educación a distancia: nuevas propuestas, nuevos interrogantes, Litwin Edith (comp.), La educación a distancia. Temas para el debate en una nueva agenda educativa, Buenos Aires, Amorrortu editores.

Martínez-Torres, M.R., Barrero, F., Toral, S.L., Gallardo, S., 2005. A digital signal processing teaching methodology using concept mapping techniques. IEEE Transactions on Education 48 (3), 422-429.

Martínez-Torres, M.R., Toral, S.L., Barrero, F., Gallardo, S., Oliva, M., Torres, T., 2008. A technological acceptance of e-learning tools used in practical and laboratory teaching, according to the European higher education area". Behavior and Information Technology 27 (6), 495-505.

Mintzberg, H., 1973. The Nature of Managerial Work. Harper Row.

Musselin, C., 2004. Towards a European academic labour market? Some lessons drawn from empirical studies on academic mobility. Higher Education 48, 55-78. 
Nunnally, J.C., 1978. Psychometric Theory, second ed. New York, McGraw Hill. Rencher, A.C. 2002. Methods of Multivariate Analysis. second ed. Wiley Series in Probability and Statistics, John Wiley \& Sons.

Sanchez, E., Garcia-Rodicio, H., 2008. The use of modality in the design of verbal aids in computer-based learning environments. Interacting with Computers 20 (6) $545-561$.

Schodorf, J.B., Yoder, M.A., Mcclellan, J.H., Schafer, R.W., 1996. Using multimedia to teach the theory of digital multimedia signals. IEEE Transaction on Education 39 (3), 336-341.

Taylor, R.L., Heer, D., Fiez, T.S., 2003. Using an integrated platform for learning to reinvent engineering education. IEEE Transaction on Education 46 (4), 409-419.

Tiffi, J.Y., Rajasingham, L., 1995. In Search of the Virtual Class: Education in an Information Society, Questia Media America, Inc.

Toral, S.L., Barrero, F., Martínez-Torres, M.R., Gallardo, S., Lillo, J., 2005 Implementation of a web-based educational tool for digital signal processing teaching using the technological acceptance model. IEEE Transaction on Education 48 (4), 632-641.

Toral, S.L., Martínez-Torres, M.R., Barrero, F., Gallardo, S., Vargas, E., Gónzalez, V., 2006. Planning a master's level curriculum according to career space recommendations using concept mapping techniques. International Journal of Technology and Design Education 16 (3), 237-252.

Toral, S.L., Barrero, F., Martínez-Torres, M.R., 2007a. Analysis of utility and use of a web based tool for digital signal processing teaching by means of a technological acceptance model. Computers \& Education 49 (4), 957-975.
Toral, S.L., Barrero, F., Martínez-Torres, M.R., Gallardo, S., 2007b. Interactive multimedia teaching of digital signal processors. Computer Applications in Engineering Education 15 (1), 88-98.

Toral, S.L., Martínez-Torres, M.R., Barrero, F., Gallardo, S., Durán, M.J., 2007c. An electronic engineering curriculum design based on concept-mapping techniques. International Journal of Technology and Design Education 17 (3), 341-356.

Toral, S.L., Barrero, F., Martinez-Torres, M.R., Gallardo, S., Duran, M.J., 2009. Modeling learner satisfaction in an electronic instrumentation and measurement course using structural equation models. IEEE Transactions on Education 52 (1), 190-199.

Toral, S.L., Martinez-Torres, M.R., Barrero, F., 2010. Reforming ICT graduate programs to meet professional needs. Computer 43 (10), 22-29.

Traub, R.E., 1994. Reliability for the Social Sciences: Theory and Applications, Thousand Oaks, California, Sage.

Trochim, W.M.K., 1989. An introduction to concept mapping for planning and evaluation. Evaluation and Program Planning 12 (1), 1-16.

Trochim, W.M.K., 1993. The Reliability of Concept Mapping. Annual Conference of the American Evaluation Association, Dallas, Texas, November 6.

Vega-Riveros, J.F., Marciales, G.P., Martínez, M., 1998. Concept maps in engineering education: a case study. Global Journal of Engineering Education 2 (1), 21-27.

Ward, J.H., 1963. Hierarchical grouping to optimize an objective function. Journal of the American Statistical Association 58, 236-244. 